\title{
Pharmacotherapeutic Management of Neuropathic Pain in End-Stage Renal Disease
}

\author{
Mena Raouf $^{a}$ Jeffrey Bettinger ${ }^{b}$ Erica W. Wegrzyn ${ }^{c}$ Roy O. Mathew ${ }^{d}$ \\ Jeffrey J. Fudin ${ }^{\mathrm{C}}$ \\ ${ }^{a}$ Department of Pain Management, Kaiser Permanente, Federal Way, WA, USA; ${ }^{b}$ Department of

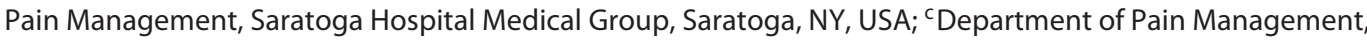 \\ Stratton VA Medical Center, Albany, NY, USA; ${ }^{d}$ Department of Nephrology, William Jennings Bryan Dorn VA \\ Medical Center, Columbia, SC, USA
}

\section{Keywords}

Neuropathic pain $\cdot$ Neuropathy $\cdot$ Opioids $\cdot$ Pain

\begin{abstract}
Background: Chronic noncancer pain is pervasive throughout the general patient population, transcending all chronic disease states. Patients with end-stage renal disease (ESRD) present a complicated population for which medication management requires careful consideration of the pathogenesis of ESRD and intimate knowledge of pharmacology. The origin of pain must also guide treatment options. As such, the presentation of neuropathic pain in ESRD can present a challenging case. The authors aim to provide a review of available classes of medications and considerations for the treatment of neuropathic pain in ESRD. Summary: In this narrative review, the authors discuss important strategies and considerations for the treatment of neuropathic pain in ESRD, including the pathogenesis of neuropathic pain, physiological changes for consideration in ESRD patients, and disease-specific consideration for medication selection. Pharmacotherapeutic classes discussed include: anticonvulsants, antiarrhythmics, antidepressants, topicals, and opioids. Key Message: Pain management in ESRD patients re-
\end{abstract}

quires careful assessment of drug-specific properties, accumulation, metabolism (presence of active/toxic metabolites), extraction by dialysis, and presence of drug - drug interactions. In the absence of pharmacokinetic data in ESRD patients, therapeutic window and potential risks should be factored in the decision making along with continued monitoring throughout therapy.

(C) 2020 The Author(s)

Published by S. Karger AG, Basel

\section{Introduction}

Chronic noncancer pain affects millions of people daily. The International Association for the Study of Pain classifies chronic pain into 3 categories including nociceptive, neuropathic, and a mixture of the $2[1,2]$. Specifically, neuropathic pain, including damage or disease to the somatosensory system, has an estimated prevalence between 6.9 and $10 \%$ of the general population and has variable causality including nerve-damaging disease states and iatrogenic origin $[2,3]$. Patients with end-stage renal disease (ESRD) comprise an important cohort of persons requiring long-term pain management, as this group has a reported chronic pain prevalence of up to 
Table 1. Symptoms of neuropathic pain [64]

\begin{tabular}{ll}
\hline Symptom & Description \\
\hline $\begin{array}{l}\text { Dysthesia } \\
\text { Paresthesia }\end{array}$ & $\begin{array}{l}\text { Unpleasant sensation } \\
\text { Abnormal sensation (burning, trickling, tingling, } \\
\text { numbness) of the skin }\end{array}$ \\
Allodynia & $\begin{array}{l}\text { Painful response to a nonpainful stimulus (e.g., } \\
\text { touch) }\end{array}$ \\
Hyperalgesia & $\begin{array}{l}\text { Increased sensitivity to pain } \\
\text { Hyperpathia }\end{array}$ \\
\hline
\end{tabular}

$92 \%$; of which approximately $35 \%$ are of neuropathic origin, and about $90 \%$ prevalence of peripheral neuropathy in those on hemodialysis (HD) [3-6]. Unfortunately, due to significant physiochemical changes that occur in patients with ESRD, lack of evidence-based pharmacologic treatment protocols, and inadequate education, this population's pain is often extremely difficult to manage. Moreover, the presence of chronic pain is an important contributor to the overall poor quality of life in patients with ESRD, as these patients report greater levels of depression. Additionally, the presence of chronic pain increases overall probability of hospitalization or death. This review identifies select pathophysiological changes and evaluates literature that has examined neuropathic pain modalities in this population [2].

\section{Neuropathic Pain}

Neuropathic pain involves damage to the somatosensory nervous system, and specifically a lesion to afferent pathways must be present for the syndrome to develop [2]. These lesions can cause a cascade of neurogenic pathologies including spontaneous ectopic nerve impulse generation, neuronal membrane excitability caused by upregulation of voltage-gated sodium channels, ectopic activity resulting in development of central sensitization, and enhanced release of excitatory amino acids and neuropeptides throughout peripheral afferent fibers [2, $7-10]$. Those excitatory amino acids lead to excitation of several receptors including $\mathrm{N}$-methyl-D-aspartate and alpha-amino-3-hydroxy-5-methyl-4-isoxazolepropionic. These varying pathologies evolve to diverse signs and symptoms of neuropathic pain, including common descriptors such as burning, numbness, tingling, and electrical-type pain, medically differentiated as dysesthesia, parasthesia, allodynia, hyperalgesia, and hyperpathia, all of which are defined in Table 1. Importantly, neuropath- ic pain differs significantly from nociceptive pain, which refers to direct tissue injury (somatic or visceral). A careful differential diagnosis can help guide targeted and individualized pharmacotherapeutic selection, as many of these pain pathologies can overlap in patients with ESRD and may prove difficult to isolate a singular cause.

General causes of neuropathic pain variously include diabetes, traumatic nerve injuries, autoimmune disorders, genetic disorders, amyloid depositions, and medications [2]. Although diabetes is the leading cause of ESRD worldwide and attributed to neuropathic pain in this population, symptoms may be compounded due to neurological changes that occur directly from kidney failure itself $[11,12]$. Central nervous system (CNS) alterations that occur in this population mainly include cognitive impairment, dementia, and stroke which often are attributed to CNS vascular injury, oxidative stress, and buildup of uremic toxins $[11,12]$. Peripheral manifestations mainly include peripheral neuropathy, which can be caused by an accumulation of uremic toxins (known as uremic neuropathy) due to their generalized nature of nerve conduction slowing effects, as well as hyperkalemia [11]. Although this review aims to focus on neuropathic pain within ESRD patients, nociceptive pain specific to ESRD can be numerous as well and include tissue damage resulting from peripheral arterial disease, bone pain from severe secondary hyperparathyroidism, or ischemic pain resulting from the presence of an arteriovenous fistula.

\section{Physiological Changes in the ESRD Population}

Although there is an abundance of pain management modalities that may be used in the treatment of neuropathic pain, physicochemical changes that occur in the ESRD population can accentuate risks of certain medications and classes of medications all of which elevate the challenge of pharmacotherapeutic considerations. Moreover, this population has been minimally studied in medical clinical trials, thus pain management is generally based on experience with consideration to pharmacokinetic and pharmacodynamic changes that occur in renal failure. Table 2 highlights alterations in pharmacokinetic properties in this setting.

Perhaps the most important manifestation of renal failure when dosing analgesics is decreased overall renal elimination of parent medications and their metabolites, in medications that require renal elimination. While this is an extremely important consideration that will impact the dosing of many medications, there are many other 


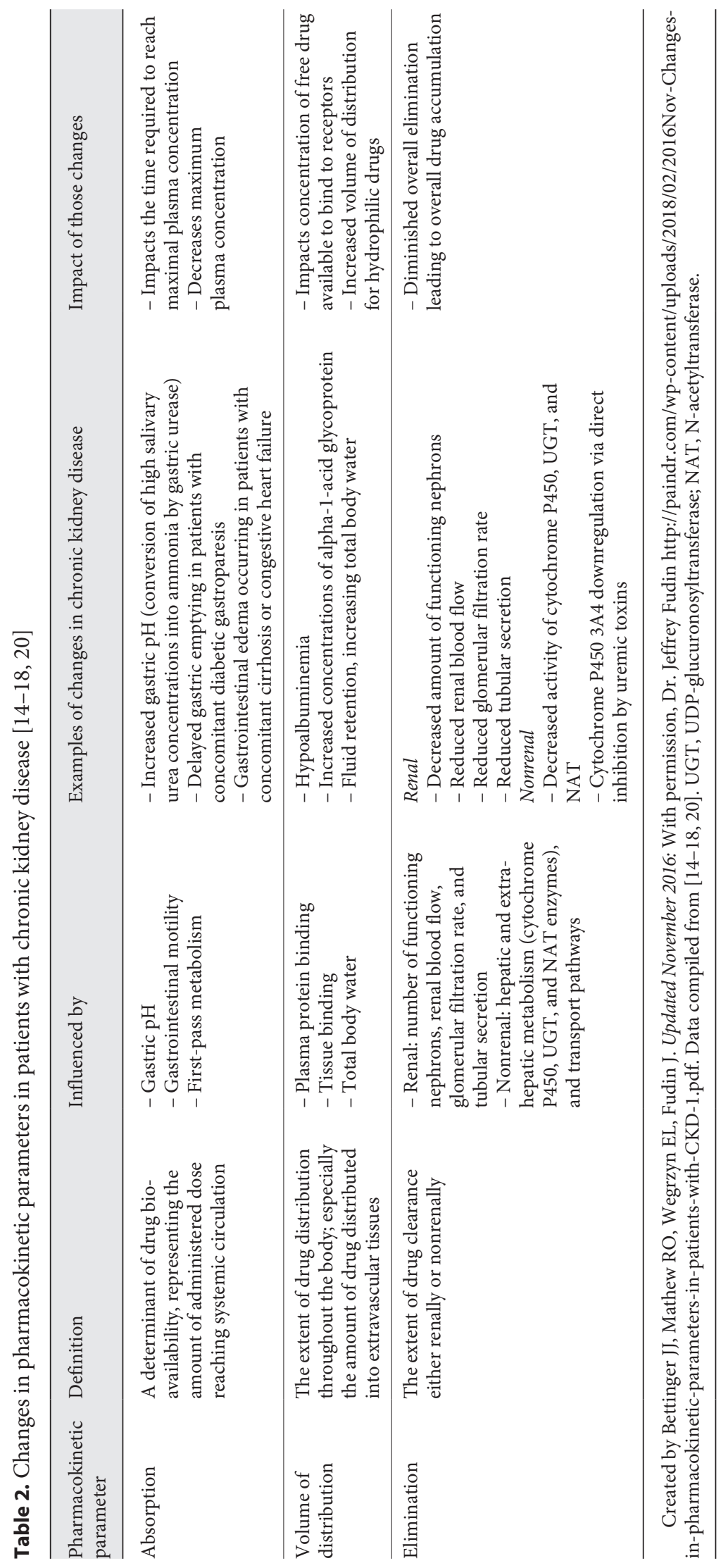




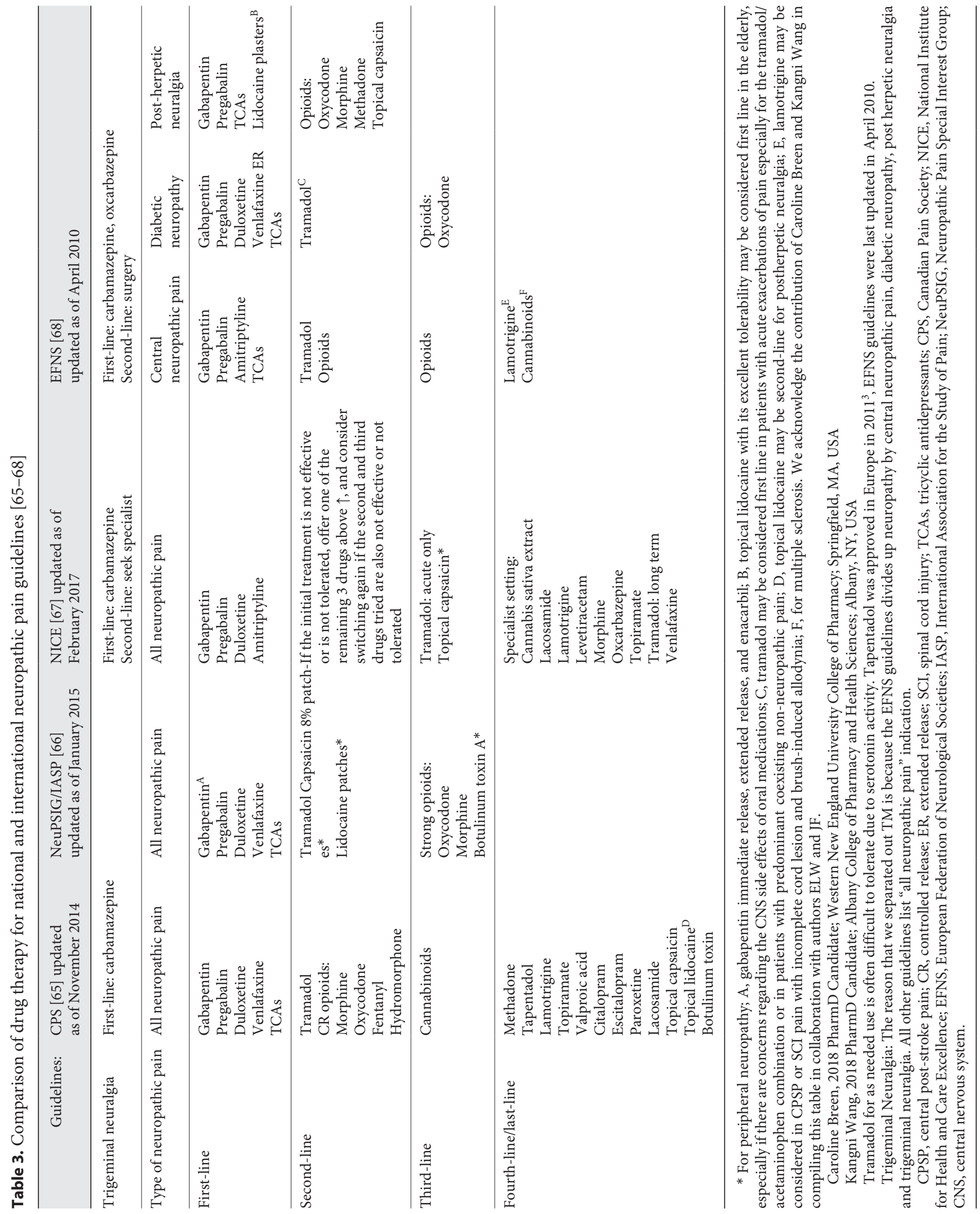


changes, which may have a broader effect on drug action, that warrant consideration in this population.

As outlined in Table 2, renal failure can lead to increases in gastric $\mathrm{pH}$, decreases in gastric motility, and changes in first-pass metabolism which all may impact overall absorption (positively or negatively), time required to reach maximum plasma concentration and overall plasma concentration and area under the concentration curve (AUC) $[13,14]$. ESRD is also associated with hypoalbuminemia, increases in concentration of alpha-1-acid glycoprotein, and increases in fluid retention which may all impact concentration of free drug available to bind with receptors and cause increased volume of distribution for hydrophilic drugs [14-17].

With renal failure, there is a progressive decrease in the amount of functioning nephrons, reduced renal blood flow, reduced glomerular filtration rate, and reduced tubular secretion, all of which decrease overall renal drug elimination and can result in accumulation of parent drug and metabolites [14, 17]. There have also been reports of nonrenal elimination disturbances associated with kidney failure, including decreased activity of cytochrome P450, UDP-glucuronosyltransferase, and Nacetyltransferase enzymes which could theoretically impact hepatic metabolism of medications [18-20]. The dialysis apparatus itself can significantly impact drug concentrations. Specific chemical characteristics of drugs that increase their removal by dialysis include lower molecular weight, minimal protein binding, lower volumes of distribution, and higher water solubilities [21].

\section{Treatment of Neuropathic Pain}

Pharmacotherapeutic options for the treatment of neuropathic pain are as varied as the pathogenesis. For instance, neuropathic pain include may include trigeminal neuralgia, diabetic neuropathy, central post stroke, or combined neuropathies [1-3]. This is evident when comparing various international guidelines for the treatment of neuropathic pain (Table 3). Three main therapeutic classes are widely accepted as first-line options for the treatment of chronic pain: anticonvulsants, serotonin-norepinephrine reuptake inhibitors (SNRIs), and tricyclic antidepressants (TCAs). The anticonvulsants are further subdivided by varied pharmacologic mechanisms, with gabapentinoids acting as stereotypical firstline agents, especially when considering that they are excreted unchanged without active or inactive metabolites.

Management of Neuropathic Pain in ESRD
Traditional opioid agonists are not generally effective in the chronic treatment of neuropathic pain; however, there are several opioids with unique mechanisms that should be considered when all other non-opioid therapies fail. It is also particularly prudent to keep these select opioids in mind for use in patients with ESRD as concomitant comorbid disease states or drug - drug interactions could present contraindications to non-opioid first-line therapies. The unique attributes of these opioids with neuropathic benefits will be discussed later in this section.

\section{Select Anticonvulsants}

Gabapentinoids

Gabapentinioids, gabapentin and pregabalin, are anticonvulsants commonly used in diabetic peripheral neuropathy and other neuropathic pain syndromes [22]. Both agents inhibit alpha-2-delta $\left(\alpha_{2} \delta\right)$ subunit of N-type voltage-gated calcium channels in the CNS, thereby reducing excitatory neurotransmitter release [23]. Despite sharing the same mechanism of action, there are key pharmacologic differences between the 2 agents. Gabapentin exhibits zero-order saturable absorption, where the bioavailability decreases as the dose increases [24]. Pregabalin has linear absorption, and therefore, more predictable pharmacokinetics. Pregabalin has 6 times higher binding affinity for the $\alpha_{2} \delta$ receptor than gabapentin.

Gabapentin and pregabalin do not undergo hepatic metabolism and are primarily eliminated unchanged in the urine $[24,25]$. Both agents require renal dose adjustments in ESRD due to potential for accumulation. The recommended dosing in ESRD for gabapentin is $300 \mathrm{mg}$ and for pregabalin is $75 \mathrm{mg}$, administered once a day [25]. The aforementioned dosing recommendations are based on population-based pharmacokinetic data and not on actual clinical trials. HD removes approximately $35 \%$ of gabapentin and $50-60 \%$ of pregabalin and supplemental doses are generally recommended post-HD [25]. One pharmacokinetic advantage is the absence of hepatic cytochrome P450 related drug - drug interactions given both medications do not undergo hepatic metabolism.

Adverse effects of particular concern in ESRD patients include sedation, cognitive impairment, and peripheral edema considering comorbid uremia and fluid retention in this population $[22,23]$. Myoclonus has been documented in ESRD patients who were taking higher than recommended doses and resolved upon discontinuation. In patients who fail to respond to the maximum recommended renal dosing of gabapentin (assuming tolerability), a trial of pregabalin may be considered due to its 
stronger binding affinity for the $\alpha 2 \delta$ receptor. In one study, substitution of gabapentin with pregabalin resulted in $25 \%$ additional pain relief in patients with normal renal function $[25,26]$.

\section{Carbamazepine}

Carbamazepine inhibits voltage-gated sodium channels and is the only anticonvulsant with a labeled indication for trigeminal neuralgia [22]. Carbmazepine is a potent enzyme inducer of various CYP450 and p-glycoprotein and is subject to many drug - drug interactions. Since CYP3A4 effects common medications, there is significant concern for drug - drug interactions that lower blood levels of the substrate drug. This is particularly concerning for patients receiving ant-retrovirals and antibiotics due to increased drug resistance, cardiac medications, and many others. Carbamazepine induces its own metabolism where its clearance increases, half-life shortens, and serum levels decrease within 1-3 weeks of initiation. For instance, the half-life for carbamazepine ranges from 10

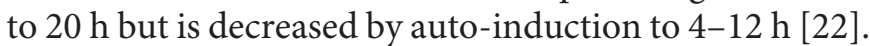
The active metabolite carbamazepine 10,11-epoxide is produced by CYP3A4 and is thought to account for hepatotoxicity. Carbamazepine promotes secretion of antidiuretic hormone, increasing thirst and water retention, which worsen coexisting fluid overload in ESRD patients [22].

There are no dose adjustments required in ESRD patients as only $1-3 \%$ of the drug is excreted unchanged in the urine $[22,27]$. Therapeutic drug monitoring is employed for efficacy and safety for epilepsy and mania, an off-label indication, but there are no defined targets for neuropathic pain. Therapeutic levels for epilepsy are 4-12 $\mu \mathrm{g} / \mathrm{mL}$ and for mania are $8-12 \mu \mathrm{g} / \mathrm{mL}$ and concentrations above $15 \mu \mathrm{g} / \mathrm{mL}$ are considered toxic [22, 27]. Close monitoring of carbamazepine and the 10,11 epoxide should be employed to mitigate toxicity.

\section{Oxcarbazepine}

Oxcarbazepine is a keto-analogue of carbamazepine that also inhibits voltage-gated sodium channels [22]. Oxcarbazepine undergoes rapid reduction to the active metabolite 10-monohydroxy metabolite (MHD). Oxcarbazepine is a weak inducer of CYP3A4 but does not affect other CYP450 enzymes nor induce its own metabolism $[22,28]$. Therefore, it has far lower drug - drug interaction potential than carbamazepine.

Oxcarbazepine is primarily eliminated in the urine, $1 \%$ as unchanged drug and $27 \%$ as the active metabolite MHD [22, 28]. The AUC of MHD is 2-2.5 fold higher in patients with ESRD compared to those with normal renal function. The package insert recommends oxcarbazepine is initiated at $50 \%$ of the recommended dose in patients with $\mathrm{CrCl}<30 \mathrm{~mL} / \mathrm{min}$ [28]. Furthermore, the immediate release formulation is recommended over the extended release in patients with ESRD [28].

Oxcarbazepine is associated with lower risk of hepatotoxicity than carbamazepine as it does not produce a 10,11 epoxide metabolite [22]. Hepatotoxicity reports with oxcarbazepine were immunologic, manifesting as drug reaction with eosinophilia and systemic symptoms syndrome rather than direct hepatic injury [29]. While oxcarabazepine is associated with lower drug - drug interactions and less hepatoxicity that carbamazepine, the incidences of SIADH and hyponatermia are more common with oxcarbazepine [30].

\section{Valproic Acid}

Valproic acid inhibits voltage-gated sodium channels and increases gamma-aminobutyric acid levels [22]. Clearance of free valproic acid is reduced by $27 \%$ in patients with $\mathrm{CrCl}<10 \mathrm{~mL} / \mathrm{min}$; however, HD removes 15 $22 \%$ of valproic acid [31]. The package insert recommends that dosage adjustments are not necessary in patients with renal failure [30]. Valproic acid is highly protein bound (90\%) where reduced protein binding in ESRD patients may increase free levels, thereby increasing risk for toxicity. Therefore, serum drug monitoring in ESRD patients may be misleading. Patients should be monitored closely for adverse effects and complications. Some adverse effects that may warrant discontinuation include hepatotoxicity, pancreatitis, significant sedation or mental status alterations, ataxia, uncontrolled tremors, or other adverse effects intolerable by the patient. Hyperammonemia has been reported with valproic acid and has been linked to hyperammonemic encephalopathy. In patients who develop unexplained changes in mental status, serum ammonia should be measured, and if elevated, valproic acid should be discontinued [30]. Of important note, the concomitant use of valproic acid with carbamazepine can increase concentrations of the carbamazepine 10,11 epoxide, thereby increasing risk for hepatotoxicity $[22,30]$.

\section{Topiramate}

Topiramate is a sodium channel inhibitor with mild inhibition of carbonic anhydrase [22]. Topiramate is 15$41 \%$ protein bound and is predominantly excreted unchanged in the urine (70\%) [32]. The typical dosing range for topiramate is $200-800 \mathrm{mg} /$ day in normal renal func- 
tion. In patient with $\mathrm{CrCl}<70 \mathrm{~mL} / \mathrm{min}$, the manufacturer recommends $50 \%$ dose reduction; however, there are no specific recommendations for ESRD [32]. HD removes $50 \%$ of topiramate, and a supplemental dose of $50 \%$ of the daily dose is recommended after HD session [22, 32]. The most common adverse effects include paresthesia, weight loss, taste perversion, somnolence, psychomotor slowing, memory impairment, and difficulty with concentration/ attention. Topiramate has been associated with acute myopia associated with secondary angle closure glaucoma with symptoms occurring within 1 month of initiation. In patients with glaucoma, topiramate should be avoided. Weight loss may be an appealing (adverse) effect in overweight or obese patients with neuropathic pain.

\section{Select Antidepressants}

As identified in the various guidelines above, antidepressants that inhibit the reuptake of serotonin $(5-\mathrm{HT})$ and norepinephrine (NE) have shown to be effective in treating neuropathic pain; with NE being the primary analgesic mediator [33]. The 2 most frequently used classes of antidepressants in neuropathic pain include TCAs and selective SNRIs.

TCAs are the more traditional class that has historically been regarded as first line with regard to neuropathic pain due to the wealth of efficacy data associated with their use. However, the major drawback to their use is related to their relatively complex pharmacology lending to a significant toxic profile. The mechanism of action includes inhibition of histamine, alpha- 1 adrenergic, and muscarinic receptors in addition to their effects on 5-HT and NE [34]. This nonselectiveness increases their propensity to cause anticholinergic, cardiac, and other undesired effects, which are even more pronounced in the elderly population in whom TCAs are not recommended based on Beer's Criteria [34, 35]. The elderly also comprise the majority of the renal disease population; therefore, SNRIs generally represent a safer option for these patients as they are more selective for 5-HT and NE reuptake transporters.

Although all SNRIs are renally cleared to a degree and all have dosing adjustments for renal impairment, duloxetine is the only one with recommendations to be avoided if creatinine clearance is $<30 \mathrm{~mL} / \mathrm{min}[36,37]$. Lobo et al. [36] specifically found that the AUC was about 2-fold higher in subjects with ESRD compared to those with normal renal function after ingestion of duloxetine. Venlafaxine is primarily metabolized through $\mathrm{O}$-demethylation via
CYP2D6 into its active metabolite O-desmethylvenlafaxine and to a lesser extent via CYP3A4 [38, 39]. Although this subjects it to drug - drug interactions with CYP2D6 inhibitors/inducers and pharmacogenomic variability, $<5 \%$ of venlafaxine and about $30 \%$ of O-desmethylvenlafaxine are excreted renally [38]. Despite this, the half-life of both venlafaxine and O-desmethylvenlafaxine has shown to be significantly prolonged in those with renal impairment and in those receiving dialysis [38]. Desvenlafaxine, the commercially available O-desmethyldesvenlafaxine metabolite, is about $45 \%$ excreted unchanged in the urine and about 55\% metabolized through phase II glucuronidation via UDP-glucuronosyltransferase enzymes $[40,41]$. This has also shown to have a prolonged half-life in those with renal impairment $[37,40]$.

Two lesser utilized SNRIs, milnacipran and levomilnacipran, are excreted renally by some degree, as about $55 \%$ of milnacipran and $58 \%$ of levomilnacipran are found unchanged in the urine $[42,43]$. Both have also shown to accumulate in those with renal impairment. Milnacipran's half-life in those with renal impairment was found to be about 3 times that of those with normal kidney function [42]. Levomilnacipran has shown to have significantly increased Cmax and AUC, as well as have a prolonged half-life in those with renal insufficiency [43]. One benefit of these, however, is that they are metabolized mainly through glucuronidation via phase II metabolites lessening their risk of drug - drug interactions.

\section{Antiarrhythmic Drugs}

Antiarrhythmic drugs with proposed analgesic effects are sodium channel blockers, also known as Class I antiarrhythmic drugs according to Vaughan-Williams classification scheme [44]. These drugs act similar to local anesthetics that inhibit sodium influx (e.g., lidocaine, bupivacaine), and subsequently, block nerve conduction. In this case, these antiarrhythmic drugs are administered systemically with the exception of lidocaine. Lidocaine is available in parenteral and topical formulations and demonstrated efficacy in postherpetic neuropathy and DPN. Mexiletine is an oral lidocaine analogue that was found to be effective in DPN [45]. The efficacy of flecainide (Class Ic) in neuropathic pain has been reported [46]. Mexiletine requires renal dose adjustments, whereas flecainide requires $50 \%$ reduction in patients with $\mathrm{CrCl}<35 \mathrm{~mL} /$ min, but no recommendations exist for ESRD patients $[47,48]$. Approximately $38-42 \%$ of flecainide is eliminated unchanged in the urine, and it is not removed by HD, which makes its pharmacokinetics less predictable in ESRD patients [49]. In our experience, prescribers are of- 
ten concerned about initiating antiarrhythmic medications due to their potential proarrhythmic effects. However, other therapies including TCAs and venlafaxine also carry this risk.

\section{Topicals}

Topical agents have the potential to deliver the medication to localized area while minimizing systemic exposure [50]. The presence of vascular and cutaneous calcifications in ESRD may interfere with their absorption, and thus hinder their efficacy. However, this will vary among patients and assessing for efficacy will be the most practical approach. Available topical medications for neuropathy include capsaicin (Zostrix) and lidocaine 5\% patches (Lidoderm). Capsaicin binds to transient receptor potential cation channel subfamily $\mathrm{V}$ member 1 and depletes substance $\mathrm{P}$ in the peripheral sensory neurons, which produces its analgesic effect [50]. Lidocaine is a local anesthetic, discussed above, available in cream, ointment, liquid, and patch formulations [44, 50]. Clonidine is a2adenergic receptor agonist that was originally approved for hypertension. Alpha-2 receptors are also present on nociceptors in the epidermis, and when activated, can downregulate the excitability of the nociceptors [51]. Topical clonidine $0.1 \%$ has demonstrated efficacy in treatment of diabetic neuropathy [52]. They are not commercially available topical clonidine product at the time of writing this manuscript, and it can be obtained through compounding pharmacies. However, topical clonidine gel is currently in the pipeline [52].

\section{Opioids}

As previously mentioned, opioids are not first line for the treatment of neuropathic pain but can be considered when first-line agents fail, such adjuvants carry a higher risk than opioids, or there are clear medical contraindications to their use. Traditional mu-opioid agonists are not generally beneficial for the long-term treatment of neuropathic pain; therefore, this section will focus on discussing the 4 opioids with unique mechanisms for reducing neuropathic pain: tramadol, tapentadol, methadone, and levorphanol.

\section{Tramadol}

At 6,000 times less the binding affinity for the mu-opioid receptor, compared to morphine, tramadol exhibits weak opioid activity [53]. In addition, however, it also inhibits the reuptake of serotonin and NE similar to SNRIs and TCAs discussed earlier. Tramadol relies heav- ily on phase I metabolism, notably CYP2D6 for metabolism to O-desmethyl-tramadol (M1) an active metabolite, and for this reason can be considered a prodrug [54]. While tramadol has been recommended by some for individuals with $\mathrm{CKD}$, the high impact of polymorphic variabilities makes it a less than desirable option due to risk for accumulation of the M1 metabolite. This is particularly important to keep in mind as only $7 \%$ of tramadol is removed during dialysis [54]. Additional caution must be given as concomitant use of tramadol with another serotonergic drug, such as a SNRI, can dramatically increase the risk for serotonin syndrome and/or lower the seizure threshold in the setting of ESRD [55].

\section{Tapentadol}

Tapentadol represents one of the most promising opioids for the treatment of neuropathic pain in ESRD. Categorized in the same chemical class as tramadol, tapentadol offers increased affinity to the mu-opioid receptor (18 times less than morphine) as well as inhibition of NE reuptake [56]. Tapentadol is a full opioid agonist, whereas tramadol is a partial opioid agonist. Despite being structurally similar, tapentadol has not been found to exhibit serotonergic activity compared to its cousin tramadol. While limited research is available on use in dialysis, in a previous publication, Atkinson et al. [21] made a case for use in dialysis patients by examining its metabolic pathway. Tapentadol is predominantly metabolized by phase II and does not have any active metabolites. Atkinson et al. [21] further hypothesized that tapentadol is likely dialyzable; however, further research is needed. When considering tapentadol's metabolism and lack of serotonergic activity that combined allow for decreased drug - drug interactions, it is a very reasonable option in the patient with ESRD.

\section{Methadone}

Methadone is an opioid offering a unique quadruple mechanism for chronic pain management as a mu-opioid agonist, NE reuptake inhibitor, N-methyl-D-aspartate antagonist, and kappa antagonist [57]. It also exhibits activity as a serotonin reuptake inhibitor. Methadone has been widely recommended for use in ESRD $[58,59]$. This is largely due to its limited dialyzability as well as compensatory excretion through the biliary - fecal route [60]. This can allow for stable pain relief in ESRD patients without a precipitous trough following dialysis. While 
mechanistically an ideal drug for ESRD, methadone has many potential drug - drug interactions through phase I CYP metabolism, which makes it a very dangerous option when starting or stopping other medications that inhibit or induce CYP enzymes. Even in patients with normal renal function, the half-life is highly variable based on phenotype and can range from 1 to 30 , and up to $150 \mathrm{~h}$ [61]. It can also substantially prolong the QTc interval, increasing the risk for torsades de pointes and sudden death. A baseline electrocardiogram should be obtained prior to initiation and monitored throughout therapy and avoidance of concomitant QTc prolonging drugs is recommended [62].

\section{Levorphanol}

Levorphanol is mechanistically identical to methadone excluding activity on 5-HT and offers similar benefits for neuropathic pain [62]. Fortunately, levorphanol avoids concerns for QTc prolongation found with methadone and has minimal drug - drug interactions as it undergoes phase II metabolism only. However, it is metabolized to the active metabolite levorphanol-3-glucuronide, which is renally excreted [63]. Similar to methadone, it has a high volume of distribution and is highly protein bound, but it has a predictable half-life in nondialysis patients of 1-17 $\mathrm{h}$, thus is likely to be minimally affected by dialysis [61].

\section{Conclusion}

Neuropathic pain is a frequent complication within the ESRD population. Management of neuropathic pain is complex, and this is compounded by an absence of ev- idence-based recommendations due to a lack of highquality studies in ESRD population. Pain management in this population requires careful assessment of drug-specific properties, accumulation, metabolism (presence of active/toxic metabolites), extraction by dialysis, and presence of drug - drug interactions. In the absence of pharmacokinetic data in ESRD patients, therapeutic window and potential risks should be factored in the decision making along with continued monitoring throughout therapy. Due to unpredicted pharmacokinetics, assessing for analgesic and adverse effects along with laboratory monitoring when indicated is important to promote efficacy and safety.

\section{Disclosure Statement}

M.R., J.B., E.W., and R.O.M.: nothing to disclose. J.F.: AceIRX Pharmaceuticals (Advisory Board); Astra Zeneca (speakers bureau); Bridge Therapeutics (Advisory Board); Daiichi Sankyo (Consultant, Advisory Board, and Speakers Bureau); Firstox Labororatories (Consultant); GlaxoSmithKline (GSK) (Advisory Board); Quest Diagnostics (Advisory Board); and ScilexPharmaceuticals (consultant).

\section{Funding Sources}

No funding or support was received by the authors for preparing this manuscript.

No funding or support was received by the authors for preparing this manuscript. This article is the sole work of the authors, and stated opinions or assertions do not reflect the opinions of employers, employee affiliates, or any pharmaceutical companies listed. It was not prepared as part of the authors' duties as federal employees.

\section{References}

1 Classification of chronic pain. Descriptions of chronic pain syndromes and definitions of pain terms. Prepared by the International Association for the Study of Pain, Subcommittee on Taxonomy. Pain Suppl. 1986;3:S1-226.

2 Baron R, Binder A, Wasner G. Neuropathic pain: diagnosis, pathophysiological mechanisms, and treatment. Lancet Neurol. 2010 Aug;9(8):807-19.

3 van Hecke O, Austin SK, Khan RA, Smith BH, Torrance N. Neuropathic pain in the general population: a systematic review of epidemiological studies. Pain. 2014 Apr;155(4):654-62.
4 Barakzoy AS, Moss AH. Efficacy of the world health organization analgesic ladder to treat pain in end-stage renal disease. J Am Soc Nephrol. 2006 Nov;17(11):3198-203.

5 Golan E, Haggiag I, Os P, Bernheim J. Calcium, parathyroid hormone, and vitamin D: major determinants of chronic pain in hemodialysis patients. Clin J Am Soc Nephrol. 2009 Aug;4(8):1374-80.

6 Brkovic T, Burilovic E, Puljak L. Prevalence and severity of pain in adult end-stage renal disease patients on chronic intermittent hemodialysis: a systematic review. Patient Prefer Adherence. 2016 Jun;10:1131-50.
7 Krishnan AV, Kiernan MC. Neurological complications of chronic kidney disease. Nat Rev Neurol. 2009 Oct;5(10):542-51.

8 Amir R, Kocsis JD, Devor M. Multiple interacting sites of ectopic spike electrogenesis in primary sensory neurons. J Neurosci. 2005 Mar;25(10):2576-85.

9 Wu G, Ringkamp M, Murinson BB, Pogatzki EM, Hartke TV, Weerahandi HM, et al. Degeneration of myelinated efferent fibers induces spontaneous activity in uninjured Cfiber afferents. J Neurosci. 2002 Sep;22(17): 7746-53. 
10 Lai J, Hunter JC, Porreca F. The role of voltage-gated sodium channels in neuropathic pain. Curr Opin Neurobiol. 2003 Jun;13(3): 291-7.

11 Ultenius C, Linderoth B, Meyerson BA, Wallin J. Spinal NMDA receptor phosphorylation correlates with the presence of neuropathic signs following peripheral nerve injury in the rat. Neurosci Lett. 2006 May;399(1-2):85-90.

12 Arnold R, Issar T, Krishnan AV, Pussell BA. Neurological complications in chronic kidney disease. JRSM Cardiovasc Dis. 2016 Nov; 5:2048004016677687.

13 Chillon JM, Massy ZA, Stengel B. Neurological complications in chronic kidney disease patients. Nephrol Dial Transplant. 2016 Oct; 31(10):1606-14.

14 Gabardi S, Abramson S. Drug dosing in chronic kidney disease. Med Clin North Am. 2005 May;89(3):649-87.

15 Nolin TD. A Synopsis of Clinical Pharmacokinetic Alterations in Advanced CKD. Semin Dial. 2015 Jul-Aug;28(4):325-9.

16 Reidenberg MM, Drayer DE. Alteration of drug-protein binding in renal disease. Clin Pharmacokinet. 1984 Jan;9 suppl 1:18-26.

17 St Peter WL, Redic-Kill KA, Halstenson CE. Clinical pharmacokinetics of antibiotics in patients with impaired renal function. Clin Pharmacokinet. 1992 Mar;22(3):169-210.

18 Nolin TD. Altered nonrenal drug clearance in ESRD. Curr Opin Nephrol Hypertens. 2008 Nov; 17(6):555-9.

19 Nolin TD, Naud J, Leblond FA, Pichette V. Emerging evidence of the impact of kidney disease on drug metabolism and transport. Clin Pharmacol Ther. 2008 Jun;83(6):898903.

20 Yeung CK, Shen DD, Thummel KE, Himmelfarb J. Effects of chronic kidney disease and uremia on hepatic drug metabolism and transport. Kidney Int. 2014 Mar;85(3):522-8.

21 Atkinson TJ, Fudin J, Wegrzyn EL, Bettinger JJ. Dialysis, Opioids, and Pain Management: where's the Evidence? Pract Pain Manag. 2014;14(8).

22 Porter RJ, Rogawski MA. Antiseizure Drugs. In: Katzung BG, editor. Basic \& Clinical Pharmacology, 14e New York: McGraw-Hill. [cited Feb 06, 2018]. Available from: http://accesspharmacy.mhmedical.com.acphs.idm. oclc.org/content.aspx? bookid=2249\&section $\mathrm{id}=175219008$.

23 Bauer CS, Tran-Van-Minh A, Kadurin I, Dolphin AC. A new look at calcium channel $\alpha 2 \delta$ subunits. Curr Opin Neurobiol. 2010 Oct; 20(5):563-71.

24 Bockbrader HN, Wesche D, Miller R, Chapel S, Janiczek N, Burger P. A comparison of the pharmacokinetics and pharmacodynamics of pregabalin and gabapentin. Clin Pharmacokinet. 2010 Oct;49(10):661-9.

25 Raouf M, Atkinson TJ, Crumb MW, Fudin J. Rational dosing of gabapentin and pregabalin in chronic kidney disease. J Pain Res. 2017 Jan;10:275-8.
26 Toth C. Substitution of gabapentin therapy with pregabalin therapy in neuropathic pain due to peripheral neuropathy. Pain Med. 2010 Mar;11(3):456-65.

27 Israni RK, Kasbekar N, Haynes K, Berns JS. Use of antiepileptic drugs in patients with kidney disease. Semin Dial. 2006 Sep-Oct; 19(5):408-16.

28 Trileptal (oxcarbazepine) [prescribing information]. East Hanover, Novartis; March 2017.

29 Planjar-Prvan M, Bielen A, Sruk A, Marusić M, Bielen I. Acute oxcarbazepine-induced hepatotoxicity in a patient susceptible to developing drug-induced liver injury. Coll Antropol. 2013 Mar;37(1):281-4.

30 Van Amelsvoort T, Bakshi R, Devaux CB, Schwabe S. Hyponatremia associated with carbamazepine and oxcarbazepine therapy: a review. Epilepsia. 1994 Jan-Feb;35(1):181-8.

31 Depakene (valproic acid) [prescribing information]. North Chicago: AbbVie Inc; October 2017.

32 Topamax (topiramate) [prescribing information]. Titusville: Janssen Pharmaceuticals Inc; June 2017.

33 Sindrup SH, Otto M, Finnerup NB, Jensen TS. Antidepressants in the treatment of neuropathic pain. Basic Clin Pharmacol Toxicol. 2005 Jun;96(6):399-409.

34 Tracy B, Sean Morrison R. Pain management in older adults. Clin Ther. 2013 Nov;35(11): 1659-68.

35 By the American Geriatrics Society 2015 Beers Criteria Update Expert Panel. American Geriatrics Society 2015 Updated Beers Criteria for Potentially Inappropriate Medication Use in Older Adults. J Am Geriatr Soc. 2015 Nov;63(11):2227-46.

36 Lobo ED, Heathman M, Kuan HY, Reddy S, O'Brien L, Gonzales C, et al. Effects of varying degrees of renal impairment on the pharmacokinetics of duloxetine: analysis of a singledose phase I study and pooled steady-state data from phase II/III trials. Clin Pharmacokinet. 2010 May;49(5):311-21.

37 Nagler EV, Webster AC, Vanholder R, Zoccali C. Antidepressants for depression in stage 3-5 chronic kidney disease: a systematic review of pharmacokinetics, efficacy and safety with recommendations by European Renal Best Practice (ERBP). Nephrol Dial Transplant. 2012 Oct;27(10):3736-45.

38 Troy SM, Schultz RW, Parker VD, Chiang ST, Blum RA. The effect of renal disease on the disposition of venlafaxine. Clin Pharmacol Ther. 1994 Jul;56(1):14-21.

39 Haanpää ML, Gourlay GK, Kent JL, Miaskowski C, Raja SN, Schmader KE, et al. Treatment considerations for patients with neuropathic pain and other medical comorbidities. Mayo Clin Proc.2010Mar;85(3Suppl):S15-25.

40 Nichols AI, Richards LS, Behrle JA, Posener JA, McGrory SB, Paul J. The pharmacokinetics and safety of desvenlafaxine in subjects with chronic renal impairment. Int J Clin Pharmacol Ther. 2011 Jan;49(1):3-13.
41 Baird-Bellaire S, Behrle JA, Parker VD, Patat A, Paul J, Nichols AI. An open-label, singledose, parallel-group study of the effects of chronic hepatic impairment on the safety and pharmacokinetics of desvenlafaxine. Clin Ther. 2013 Jun;35(6):782-94.

42 Puozzo C, Pozet N, Deprez D, Baille P, Ung HL, Zech P. Pharmacokinetics of milnacipran in renal impairment. Eur J Drug Metab Pharmacokinet. 1998 Apr-Jun;23(2):280-6.

43 Chen L, Greenberg WM, Brand-Schieber E, Wangsa J, Periclou A, Ghahramani P. Effect of renal impairment on the pharmacokinetics of levomilnacipran following a single oral dose of levomilnacipran extended-release capsule in humans. Drug Des Devel Ther. 2015 Jun;9:3293-300.

44 Tremont-Lukats IW, Challapalli V, McNicol ED, Lau J, Carr DB. Systemic administration of local anesthetics to relieve neuropathic pain: a systematic review and meta-analysis. Anesth Analg. 2005 Dec;101(6):1738-49.

45 Oskarsson P, Ljunggren JG, Lins PE; The Mexiletine Study Group. Efficacy and safety of mexiletine in the treatment of painful diabetic neuropathy. Diabetes Care. 1997 Oct; 20(10):1594-7.

46 von Gunten CF, Eappen S, Cleary JF, Taylor SG 4th, Moots P, Regevik N, et al. Flecainide for the treatment of chronic neuropathic pain: a Phase II trial. Palliat Med. 2007 Dec;21(8): 667-72.

47 Mexiletine hydrochloride [prescribing information]. North Wales: Teva Pharmaceuticals USA, Inc; March 2015.

48 Flecainide Acetate [prescribing information]. Bridgewater: Amneal Pharmaceuticals; September 2017.

49 Holmes B, Heel RC. Flecainide. A preliminary review of its pharmacodynamic properties and therapeutic efficacy. Drugs. 1985 Jan; 29(1):1-33

50 Argoff CE. Topical analgesics in the management of acute and chronic pain. Mayo Clin Proc. 2013 Feb;88(2):195-205.

51 Maze M, Tranquilli W. Alpha-2 adrenoceptor agonists: defining the role in clinical anesthesia. Anesthesiology. 1991 Mar;74(3):581-605.

52 Campbell CM, Kipnes MS, Stouch BC, Brady KL, Kelly M, Schmidt WK, et al. Randomized control trial of topical clonidine for treatment of painful diabetic neuropathy. Pain. 2012 Sep;153(9):1815-23.

53 Smith HS. Opioids and neuropathic pain PainPhysician.2012Jul;15(3Suppl):ES93-110.

54 Miotto K, Cho AK, Khalil MA, Blanco K, Sasaki JD, Rawson R. Trends in tramadol: pharmacology, metabolism, and misuse. Anesth Analg. 2017 Jan;124(1):44-51.

55 Volpi-Abadie J, Kaye AM, Kaye AD. Serotonin syndrome. Ochsner J. 2013;13(4):53340.

56 Vadivelu N, Huang Y, Mirante B, Jacoby M, Braveman FR, Hines RL, et al. Patient considerations in the use of tapentadol for moderate to severe pain. Drug Healthc Patient Saf. 2013 Jul;5:151-9. 
57 Fudin J, Raouf M, Wegrzyn EL. Pharmacological Considerations Regarding Equianalgesic Dosing. A White Paper from the Academy of Integrative Pain Management. September 2017.

58 Dean M. Opioids in renal failure and dialysis patients. J Pain Symptom Manage. 2004 Nov; 28(5):497-504.

59 Pham PC, Toscano E, Pham PM, Pham PA, Pham SV, Pham PT. Pain management in patients with chronic kidney disease. NDT Plus. 2009 Apr;2(2):111-8.

60 Kreek MJ, Schecter AJ, Gutjahr CL, Hecht M. Methadone use in patients with chronic renal disease. Drug Alcohol Depend. 1980 Mar; 5(3):197-205.

61 Pham TC, Fudin J, Raffa RB. Is levorphanol a better option than methadone? Pain Med. 2015 Sep;16(9):1673-9.
62 Chou R, Cruciani RA, Fiellin DA, Compton P, Farrar JT, Haigney MC, et al.; American Pain Society; Heart Rhythm Society. Methadone safety: a clinical practice guideline from the American Pain Society and College on Problems of Drug Dependence, in collaboration with the Heart Rhythm Society. J Pain. 2014 Apr;15(4):321-37.

63 Prommer E. Levorphanol: revisiting an underutilized analgesic. Palliat Care. 2014 May; $8: 7-10$

64 International Association for the Study of Pain. IASP Taxonomy. December 14, 2017. [Accessed March 1, 2018]. Available from: https://www.iasp-pain.org/Education/Content.aspx?ItemNumber $=1698 \&$ navItemNum ber $=576$.
65 Moulin D, Boulanger A, Clark AJ, Clarke H, Dao T, Finley GA, et al. Pharmacological management of chronic neuropathic pain: revised consensus statement from the Canadian Pain Society. Pain Res Manag. 2014 Nov-Dec; 19(6):328-35.

66 Finnerup NB, Attal N, Haroutounian S, McNicol E, Baron R, Dworkin RH, et al. Pharmacotherapy for neuropathic pain in adults: a systematic review and meta-analysis. Lancet Neurol. 2015 Feb;14(2):162-73.

67 National Institute for Health and Care Excellence (NICE). Neuropathic pain: the pharmacological management of neuropathic pain in adults in non-specialist settings. 2013.

68 Attal N, Cruccu G, Baron R, Haanpää M, Hansson P, Jensen TS, et al.; European Federation of Neurological Societies. EFNS guidelines on the pharmacological treatment of neuropathic pain: 2010 revision. Eur J Neurol. 2010 Sep;17(9):1113-e88. 